\title{
CONHECIMENTOS, VALORES E VIVÊNCIAS DE ADOLESCENTES ACERCA DAS DOENÇAS DE TRANSMISSÃO SEXUAL E AIDS
}

\section{ADOLESCENTS' KNOWLEDGE, VALUES AND PRACTICES REGARDING SEXUALLY TRANSMITTED DISEASES AND AIDS}

\author{
Edir Nei “Teixeira Mandú * \\ Áurea Christina de Paula Corrêa ** \\ Maria Aparecida Vieira
}

MANDU, E.N.T.; CORRÊA, A.C.d.R; VIEIRA, M.A. Conhecimento, valores e vivências de adolescentes acerca das doenças de transmissão sexual e AlDs. Rev Bras Cresc Desenu Hum, São Paulo, 10(1),2000.

Resumo: Neste artigo, discutimos conhecimentos, valores e práticas de adolescentes frente às DSTs/AIDS e sua prevenção. A partir de dados de pesquisa, chamamos atenção para a dissociação entre ter informação e a adoção de comportamentos de prevenção. Complementarmente, apresentamos alguns elementos $\wedge$ fiunda $\wedge$ Tnentais no encaminhamento de práticas educativas junto a adolescentes, levando em consideração a necessidade de integração entre conhecimento, afetividade e aspectos socioculturais.

Palavras-chave: DST/AIDS; educação sexual; sexualidade; adolescência.

\section{APRESENTAÇÃO}

As discussões presentes neste artigo referem-se à problemática das DSTs e AIDS na adolescência. Inicialmente, refletimos sobre conhecimentos, valores e práticas de adolescentes mulheres de segmentos populares frente a tais problemas, a partir da comunicação de dados de pesquisa, e, de modo complementar, tecemos algumas considerações acerca da educação sexual como alternativa ao seu enfrentamento.

Esta produção relaciona-se a nossas experiências com educação sexual em escolas de comunidades pobres de Cuiabá, Mato Grosso. Em 1997, buscando uma abordagem apropriada da questão via práticas educativas, desenvolvemos um estudo voltado à compreensão dos simbolismos e vivências de adolescentes mulheres frente às DSTs/AIDS e anticoncepção. Neste artigo, apresentamos apenas parte dos dados analisados, os relacionados à questão das DSTs/ AIDS e práticas sexuais de prevenção de riscos, e a partir destes, valorizando a inter-relação saúde-sexualidade-educação, debatemos alguns elementos essenciais a serem considerados no encaminhamento de práticas de educação sexual junto ao grupo.

\section{A PROBLEMÁTICA DAS DSTs/AIDS NAADOLESCENCIA}

A importância da temática em foco pode ser evidenciada, a princípio, a partir de dados epidemiológicos relativos ao modo como as DSTs/ AIDS atingem a população e, especificamente, os adolescentes.

\footnotetext{
* Enfermeira, doutorando em enfermagem, docente da Faculdade de Enfermagem e Nutrição da Universidade Federal de Mato Grosso.

** Enfermeiras, mestrandas em enfermagem em saúde pública, docentes da Faculdade de Enfermagem e Nutrição da Universidade Federal de Mato Grosso.
} 
A AIDS é uma epidemia cujo crescimento mundial não pode ser desconsiderado. O Brasil encontra-se, hoje, entre os quatro países com maior número de casos registrados, segundo dados do Programa Global de AIDS da Organização Mundial da Saúde. As notificações realizadas junto ao Ministério da Saúde, até fevereiro 1998, revelavam 129.000 casos de AIDS (dado sem correção de atraso de notificação) em todo o território nacional (BRASIL, 1998).

Inicialmente considerada uma doença de homo e bissexuais, hoje a AIDS atinge os diferentes sexos. Dados estatístícos revelam não só a sua extensão a heterossexuais, como também a sua rápida feminização. No Brasil, até 1984, 69\% dos casos de AIDS notificados eram relativos à sub categoria de exposição homo e bissexual. Em 1996, esse percentual caiu para 44\%. Em 1985, a proporção de casos homem/mulher era de 28/1 e em 1997/98 essa proporção diminuiu para 2/1 (BRASIL, 1998).

No período de 1980-1997, a AIDS no Brasil atingiu, na faixa etária de 10 a 14 anos, 276 homens ( $0,3 \%$ do total de homens acometidos) e 72 mulheres ( $0,3 \%$ do total de mulheres acometidas); na faixa etária de 15 a 19 anos, atingiu 1.843 homens (2,0\% do total de homens acometidos) e 688 mulheres (2,8\% do total de mulheres acometidas). Entre os casos ocorridos entre 10 e 14 anos, 18 foram relacionados a práticas heterossexuais, 10 a relações homo e bissexuais e 5 ao uso de drogas e relações homo e bissexuais; entre 15 e 19 anos, 464 casos foram relacionados a relações heterossexuais, 235 à exposição a relações homossexuais, 141 a relações bissexuais e 87 ao uso de drogas e relações homo e bissexuais (BRASIL, 1997a).

Inicialmente, a maioria dos adolescentes que se contaminou pelo vírus da AIDS era do sexo masculino, através da transfusão sangüínea. Para as adolescentes mulheres, até recentemente, o uso de drogas injetáveis era o mais importante fator de risco. Contudo, esse perfil alterou-se. Não só aumentaram os casos de AIDS/contaminação pelo HIV na adolescência de homens e mulheres, como também as relações sexuais (hetero e homossexuais) aparecem como a principal via de contaminação (BRASIL, 1997a). A partir de então, evidencia-se, de modo incontestável, a relevância da relação DSTs/AIDS - exercício da sexualidade na adolescência.

Segundo o Ministério da Saúde, desde o início da epidemia, o grupo etário mais atingido tem sido o de 20 a 39 anos, correspondendo a $71 \%$ dos casos notificados até Fevereiro de 1998, com progressivo aumento da freqüência relativa entre os mais jovens (20-29 anos) e tendência à estabilização após 1991 (BRASIL, 1998). Em todo o mundo, estima-se que, em 1997, ocorreram 16.000 casos novos de infecção pelo HIV - mais de $50 \%$ entre a faixa de idade de 16 a 24 anos (BRASIL, 1997b). Estes dados são significativos e permitem inferir, ao se levar em conta o período de incubação do vírus HIV, média de 10 anos, que a contaminação pelo vírus ocorreu, provavelmente, na adolescência.

Em Mato Grosso, os casos diagnosticados de AIDS até o ano de 1998 chegaram a 1.453. Entre os anos 1987 e 1998, foram registrados 1.301 casos na faixa etária de 13 a 45 anos - 930 casos entre homens e 371 entre mulheres, numa razão por sexo de 3/1 (MATO GROSSO, 1999). No ano de 1987 foram diagnosticados 23 casos, numa razão homem/mulher de 22/1 (MATO GROSSO, 1997); em 1998, foram notificados 139 casos, modificando-se a razão por sexo para 21/1 (MATO GROSSO, 1999). Segundo o Ministério da Saúde, os casos notificados representam apenas $25 \%$ dos casos de AIDS existentes e, para cada caso existente, estima-se que haja mais de 5 pessoas infectadas pelo HIV. Assim, calcula-se que o Estado possua em torno de 5.812 casos de AIDS e cerca de 29.060 soropositivos (que não constam das estatísticas oficiais).

Considera-se o Estado de Mato Grosso como de média endemicidade-entre 1990-1997 a incidência média de AIDS entre a população foi de 7,2 casos/100.000 habitantes, a sétima entre as maiores do País. Entretanto, o rápido crescimento da AIDS no Estado coloca-o como o segundo de maior crescimento em todo o território nacional - de 1,51 casos ano/100.000 habitantes (BRASIL, 1997a).

Entre todos os casos ocorridos no perÍodo 1990-1998, um total de 1.453, as relações heterossexuais foram a principal via de contaminação pelo HIV, tanto para homens - 347 casos, quanto para mulheres - 183 casos; as relações homossexuais foram o segundo tipo de exposição mais freqüente para os homens - representando 108 casos, e o tipo heterossexual/hemofílico para as mulheres - representando de 58 casos. Estes dados, contudo, não abrangem 246 casos entre os homens e 94 entre mulheres (23,3\% do total de casos), que têm a via de contaminação ignorada (MATO GROSSO, 1999).

A doença registrada no Estado de Mato Grosso atinge principalmente o município de Cuiabá. A incidência média de casos de AIDS na capital, entre 90-97, encontra-se em torno de 21 casos/ 100.000 habitantes, correspondendo a $60 \%$ dos casos notificados no Estado para o período (BRASIL, 1997b). Entre 1980 e 1988 foram diagnosticados 149 casos de AIDS no município, nú- 
mero que se ampliou para 193 só no ano de 1996, correspondendo a um aumento de incidência de 18.8/100.000 hab. para 41.6/100.000 hab. (BRASIL, 1997a).

No período de 1980-1998 foram registrados, em Mato Grosso, 83 casos de AIDS na faixa etária de 13 a 19 anos e 550 casos entre 20-29 anos. A principal via de contaminação para essas faixas etárias foi a heterossexual e hetero/ hemofílico, correspondendo respectivamente a 28 e 11 casos, entre 13 e 19 anos. e 191 e 89 casos entre 20-29 anos. Nestas faixas etárias, também, o desconhecimento da via de contaminação é alta, chegando a 24 e 127 casos, respectivamente (MATO GROSSO, 1999).

Os dados de Mato Grosso também revelam a feminização da doença e a via sexual (hetero e homossexual) como a mais freqüente no desenvolvimento da epidemia da AIDS. Os casos, cuja contaminação pelo HIV provavelmente ocorreu na adolescência (os da faixa etária de 20-29 anos), representam um número significativo entre o total dos casos de AIDS no Estado. Nos anos 8098, entre menores de 12 anos, há registros de 43 casos; na faixa etária de 13 a 29 anos encontramos 633 casos; acima dos 30 anos há 778 casos diagnosticados (MATO GROSSO, 1999).

No que se refere às demais DSTs, as estatísticas nacionais e estaduais existentes não permitem a identificação do modo como adolescentes estão a elas expostas. Em 1998 foram notificados 20.010 casos de DST em todo o Estado. Só em dezembro de 1998 ocorreram 1.214 casos, sendo 186 casos em Cuiabá (MATO GROSSO, 1999). Em 1997 foram notificados 46 casos diagnosticados de DST na faixa etária de 13 a 19 anos, 19 destes em mulheres (MATO GROSSO, 1997).

Podemos aventar, no entanto, que o número de DSTs na adolescência no município é muito mais significativo, se considerarmos que há uma sub-notificação por parte dos serviços, que nem sempre o diagnóstico dessas doenças é realizado corretamente e que o grupo em questão (assim como outros) nem sempre recorre aos serviços para diagnóstico e resolução de seus problemas de saúde. Estudo realizado em 1996, com adolescentes de 12 a 17 anos que viviam nas ruas em Cuiabá, aponta que $83,3 \%$ possuíam algum tipo de DST e que 33,3 \% eram positivos para o HIV (CORRÊA DA COSTA, 1996).

As repercussões das DSTs/AIDS, para o acometido, são inúmeras. Elas incluem a culpa, a discriminação, o sigilo, o não tratamento dos problemas, mudanças de comportamento social e sexual e complicações orgânicas, que podem levar à morte (CANELLA, 1988). No âmbito social, os impactos desses problemas vão além do que os números por si podem indicar. No mundo todo, sobretudo a AIDS tem gerado transformações socioculturais e envolvimento político-econômico. Políticas envolvendo pesquisa, produção de tecnologia de diagnóstico e tratamento e a implementação de ações e estratégias têm consumido significativos recursos humanos e financeiros dos vários países (PARKER, 1997).

Embora os dados apresentados não expressem as diferenças derivadas das condições sociais dos adolescentes, sabe-se que entre os das camadas mais pobres as repercussões das DSTs/AIDS são maiores, em função da falta de acesso que esses grupos têm a recursos médico-sociais. Os grupos desfavorecidos economicamente, como é o caso das adolescentes que participaram desta investigação, têm a sua vida limitada por inadequadas condições (incluindo dificuldades de acesso aos serviços de saúde, à educação, à renda, entre outras), o que pode significar que, entre estes, as conseqüências dos problemas de saúde mencionados são certamente mais difíceis de serem enfrentadas.

As DSTs/AIDS não se constituem problemas isolados do contexto de vida dos vários grupos sócio etários. Entre os adolescentes, eles relacionam-se a processos socioculturais que, direta ou indiretamente, articulam-se às suas vivendas.

$\mathrm{O}$ acometimento das DSTs/AIDS, nesta fase da vida, é resultado da complexa interação entre saúde, sexualidade adolescente e contexto sociocultural (ARILHA \& CALAZANS, 1998; PIMENTA, PASSARELLI, SANTOS \& NEGRÃO, 1998).

Um dos processos do contexto que se pode evidenciar é o de mudanças culturais no campo da sexualidade, em curso em nossa sociedade, sobretudo após os anos 60. Transformações culturais relativas ao exercício da sexualidade têm resultado em novos valores e comportamentos sexuais entre os diferentes grupos e, no que nos interessa aqui, entre os adolescentes (CAVAL-CANTI, 1988). Pode-se destacar, desse conjunto, o início cada vez mais precoce das atividades sexuais, que vem colocando os jovens em contato com novos desafios e problemas no campo da saúde-doença. A “liberação” do relacionamento sexual entre adolescentes, a despeito do que se considere conquista, é um dos processos relacionados à difusão das doenças transmitidas através de práticas sexuais, sobretudo porque uma maior precocidade na vida sexual e a experiência com diferentes parceiros não se fez acompanhar por um equivalente acesso à educação e ao acompanhamento da saúde sexual. 
As DSTs/AIDS na adolescência articulamse ao modo como se dá o exercício da sexualidade. Este campo, por sua vez, abrange conhecimentos, valores, desejos e comportamentos definidos e redefinidos na estrutura familiar e, mais amplamente, no campo social (PARKER, HERDT \& CARBALLO, 1995).

A construção da sexualidade é um processo que ocorre ao longo da vida, sobretudo de modo assistemático, nos contatos da criança com os pais, familiares e com outros, quando valores e comportamentos sexuais socialmente estabelecidos se definem/redefinem. A sexualidade não se estrutura na adolescência mas ao longo do desenvolvimento da criança, nas vivências - na interação com o meio, nos contatos físicos, nos vínculos afetivos com os pais e outros, no brincar, nos jogos sexuais, nas descobertas, na criação, no processo de estruturação de relações de dependência/independência e no processo de estruturação da identidade masculinal/feminina (SILVA, 1995).

Desse ponto de vista, evidenciam-se a participação da família, da escola, dos meios de comunicação, do setor saúde e de outras instituições sociais, embora se possa destacar que o modo como a família lida com as questões ligadas ao exercício da sexualidade condiciona fortemente a aprendizagem das crianças e adolescentes. Podese dizer que a preparação para o seu exercício começa na infância e depende largamente dos pais (CONCEIÇÃO, 1988).

Assim, a forma como os adolescentes encaram e lidam com o próprio corpo, com o corpo do outro, com afetos, com desejos e, numa perspectiva mais global, o modo como eles vêem o mundo e seus processos, e o modo como eles se comportam no campo sexual, leva-os a se defrontarem ou não com as DSTs/AIDS e à possibilidade de preveni-las.

Um outro processo intrinsecamente relacionado às DSTs/AIDS na adolescência refere-se à qualidade da assistência médico-sanitária (PIMENTA, PASSARELLI, SANTOS \& NEGRÃO, 1998). Na maioria dos municípios brasileiros (e aqui se inclui Cuiabá), a assistência pública à saúde do grupo (assim como a dos demais) é precária. Os adolescentes não encontram nos serviços de saúde e em outros o suporte adequado, seja em relação à educação sexual, a recursos preventivos das doenças em questão ou ao acompanhamento de sua saúde.
Em relação ao grupo feminino, essa problemática incorpora ainda o fato de os serviços de saúde freqüentemente desconsiderarem necessidades e problemas derivados das desigualdades de gênero, como largamente denunciado pelos movimentos feministas, o que atinge de modo específico a saúde e o exercício da sexualidade de adolescentes mulheres. Geralmente, as medidas públicas de prevenção das DSTs/AIDS, encaminhadas através dos serviços de saúde, não só são desarticuladas de ações mais globais voltadas à saúde sexual e reprodutiva das mulheres (assim como à saúde dos homens), como também desconsideram o modo como se reproduzem as relações de dominação da mulher e as repercussões sobre sua saúde.

Mas, esses são alguns dos fatores socioculturais relacionados às DSTs/AIDS na adolescência. Não se pode obscurecer o fato de que esses problemas de saúde, em última análise, articulam-se ao acesso a determinadas condições sociais - a recursos e bens sociais em geral que conformam as condições de vida e saúde e o exercício da sexualidade humana/adolescente.

\section{SABERES E PRÁTICAS DE ADOLESCENTES A CERCA DAS DSTS/AIDS - DADOS DE PESQUISA}

\section{Estratégias metodológicas da investigação}

$\mathrm{O}$ estudo que apresentamos, de natureza qualitativa, partiu das seguintes indagações: como adolescentes mulheres, que vivem em uma dada realidade, interpretam e vivenciam a possibilidade de adquirir uma DST/AIDS? Que contradições estão presentes em seus discursos e práticas?

Buscava-se reconhecer e analisar os saberes e vivências desse grupo no campo da sexualidade, particularmente os seus conhecimentos, valores e práticas relacionadas às DSTs/ AIDS, através do olhar sobre o seu universo discursivo.

Tomamos por referência empírica o discurso de 24 adolescentes do sexo feminino das camadas populares, com idade entre 13 e 19 anos, moradoras de uma área periférica da cidade de Cuiabá - o Pólo Osmar Cabral ${ }^{1}$. Os critérios preestabelecidos para constituição dos sujeitos desta pesquisa foram: ter idade entre 10 e 19 anos; ser do sexo feminino; residir na área do Pólo Osmar Cabral; aceitar participar do estudo. Na eleição desses critérios considerou-se o fato de

1 O pólo Osmar Cabral compreende os Bairros São João Del Rey, Osmar Cabral, Fortaleza e Santa Laura, numa extensão de aproximadamente 1.000.000 metros quadrados. São bairros periféricos, com pequena infra-estrutura urbana, situados a cerca de $20 \mathrm{Km}$ do centro de Cuiabá. Sua população estimada em ^1997 era de cerca de 13.831 habitantes. (Cuiabá, Fundação de Saúde, 1998). 
que adolescentes com esse perfil constituíam parte do grupo para o qual planejávamos o desenvolvimento de práticas educativas no campo da sexualidade.

Para captar os conhecimentos e valores desse grupo, em relação à problemática eleita, utilizamos como técnica a entrevista aberta, orientada por um roteiro contendo questões em torno de quatro temas básicos: experiências sexuais; vivências com os problemas DSTs/ AIDS; conhecimentos acerca das DSTs/AIDS (doenças, problemas decorrentes, transmissão, prevenção); práticas sexuais preventivas.

A seleção do grupo de adolescentes ocorreu a partir da intermediação de agentes comunitárias de saúde que atuam na localidade ou se deu através de uma abordagem direta em escolas e no centro de saúde local. Utilizamos como estratégia inicial um contato informal, tendo em vista a constituição dos sujeitos da pesquisa. Para a coleta das informações, estendemos esse contato a um segundo momento, ocasião em que realizamos normalmente a entrevista proposta.

A classificação dos dados subjetivos foi realizada de acordo com as questões de pesquisa e objetivos construídos. Para tal, tomamos por referência analítica uma compreensão ampla da sexualidade adolescente, referida ao universo cognitivo, afetivo e ao contexto sócio cultural específico do grupo.

No processo de classificação dos dados fizemos uma análise cuidadosa do material escrito, valorizando palavras, frases, articulação de idéias e sentido geral do texto. Na classificação e interpretação dos dados, adotamos os seguintes passos (GOMES, 1994): organização inicial mais abrangente; classificação minuciosa orientada pelas questões de estudo e outras construídas junto ao próprio texto; formação de conjuntos de informações segundo a heterogeneidade das comunicações (que resultaram nas categorias/sub-categorias empíricas apresentadas em conhecimentos, valores e vivências das adolescentes sobre DSTs/ AIDS); confronto contínuo com a teoria.

\section{Sujeitos do estudo}

Participaram da pesquisa onze adolescentes com idade entre 13 e 15 anos e treze com idade entre 16 e 19 anos (selecionadas a partir dos critérios apontados acima). Por ocasião do levantamento dos dados, seis das participantes tinham completado ou faziam a primeira etapa do primeiro grau (primeira a quarta série); quinze ainda não haviam terminado a segunda etapa (quinta a oitava série); três cursavam o segundo grau. Treze adolescentes estavam fora da escola. As que estudavam, o faziam em escolas públicas locais. Cin- co das adolescentes entrevistadas já participavam do mercado de trabalho. Estas, não só tinham abandonado a escola, como não viam a possibilidade de retomar os estudos.

Oito delas tinham um companheiro (marido, parceiro ou namorado com quem mantinham relações sexuais); nove já eram mães (estavam grávidas oujá tinham filhos). Apenas quatro adolescentes tinham suas próprias famílias; as demais viviam com os pais ou mães. Entre todas, quatorze já tinham tido ou mantinham atividade sexual. Entre cinco adolescentes, as práticas sexuais tinham sido iniciadas antes dos 15 anos de idade. Apenas as que tinham um companheiro referiam práticas sexuais regulares.

\section{Conhecimentos, valores e vivências das adolescentes sobre DSTs/AIDS}

\section{DSTs/AIDS-problemas (des)conhecidos?}

\section{Informação e desinformação}

As DSTs não são problemas completamente desconhecidos para o grupo que participou deste estudo. Porém, informação e desinformação misturam-se nos depoimentos analisados. À pergunta sobre o que sabiam a respeito das doenças transmitidas através das relações sexuais, suas respostas foram curtas, parciais e, às vezes, equivocadas. Referiram apenas ter ouvido falar de algumas das DSTs (a AIDS, a sífilis, a gonorréia e o cancro mole), reportando-se a supostas manifestações orgânicas e ao modo como podem ser transmitidas/evitadas:

"Bem, a que eu mais conheço é a AIDS, mas tem também a sífilis. A gente pode pegar uma através do sexo, quando não usa camisinha" (Entrevista 9).

"Eu já ouvi falar dessa crista de galo, ela cresce o caroço e quando cai fica aquele buraco, então ela vai virando uma ferida e ela acaba pegando câncer" (Entrevista 4).

Para algumas, as DSTs são praticamente desconhecidas, pois chegam a negar qualquer informação sobre o modo como estas podem ser adquiridas, sobre os problemas que podem causar ou mesmo sobre o modo como podem ser percebidas ou evitadas:

"Eu sei que pega (as DSTs) quando transa, não é mesmo? ... Só assim. Mas eu não se mais nada não" (Entrevista 2).

As DSTs, à exceção da AIDS, são problemas que parecem praticamente não fazer parte das vivências das adolescentes. Quando lhes perguntamos se além de ouvir falar já tinham tido contato, visto ou adquirido o que chamam de doença venérea, apenas algumas delas responderam que conheciam alguém com o problema, mas que nunca tiveram um contato mais próximo com o problema. 
Sobre as DSTs percebemos que o grupo detém poucas informações, além de não ter qualquer experiência mais próxima. Manifestam uma certa negação da possibilidade de elas fazerem parte de suas vidas, mesmo entre as adolescentes que já haviam iniciado as atividades sexuais. As DSTs, ainda que reconhecidas como um possível problema para a saúde, são referidas como algo distante, sobre as quais pouco têm a dizer, não representando para suas vidas uma possível ameaça.

O mesmo não ocorreu em relação à AIDS. No material analisado, encontramos a AIDS como a mais conhecida entre as doenças de transmissão sexual ou a que mais se aproxima da vivência das adolescentes. Sobre ela as entrevistadas apresentam falas mais afirmativas, um maior número de informações e mostram-se mais à vontade para conversar sobre o que sabem, sentem ou pensam acerca do problema.

É provável que, em parte, esse achado possa ser explicado pelo falo de a AIDS representar o risco de morte e por vir acompanhada de um conjunto de estereótipos em relação ao exercício da sexualidade, que a colocam em evidência. Também, entre as DSTs, aAIDS tem sido uma das mais abordadas pelos meios de comunicação, sobretudo pela televisão, que chama atenção (nem sempre de modo adequado) para a gravidade do problema (CASTRO, 1995). Diferentemente do que ocorre em relação às DSTs em geral, vários meios de comunicação socializam conhecimentos sobre a AIDS (e a sua gravidade) entre a população, através da divulgação de casos ocorridos entre pessoas públicas, pela exposição a riscos e medidas de prevenção, mediante a divulgação de tecnologias para o seu enfrentamento, entre outros processos.

A AIDS é percebida pelas adolescentes como uma doença progressiva, associada inevitavelmente à morte. É vista por elas como um problema grave, perigoso e feio:

\footnotetext{
"A AIDS é uma doença venérea, que vai matando a gente por dentro, vai com o tempo, ela não é dessas doenças que a gente pega e já morre na hora, ela vai matando a gente devagarzinho por dentro, vai destruindo tudo por dentro da gente” (Entrevista 19).

"É uma doença muito feia, ela consegue acabar com a pessoa a qualquer hora” (Entrevista 18).
}

Este achado é similar ao encontrado em estudos como o de GUIMARÃES (1994), que refere amenção de mulheres adultas à presença de sentimentos de medo e a percepção de fatalidade ligados à AIDS, e o de OLIVEIRA ( 1992), que refere expressões sobre a AIDS como "feia, ruim, maldita, que dá medo, teimosa”.
Sobre os conhecimentos das entrevistadas acerca do modo como pode se dar a contaminação pelo HIV, a principal referência encontrada foi à via sexual. Algumas acrescentam a esta, a via perinatal e a sangüínea. Encontramos também menção ao contato direto com pessoas ou objetos como uma possível via de transmissão:

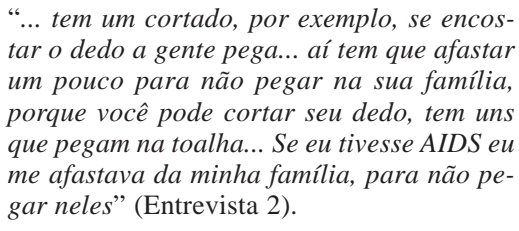

Os meios de comunicação têm freqüentemente divulgado os modos pelos quais a doença em questão é transmitida. Na busca de romper com o preconceito que gera isolamento das pessoas com AIDS, chama-se atenção para o fato de que a proximidade/o contato não sexual é seguro e desejado no enfrentamento da epidemia. Mas, o que pudemos constatar nesta pesquisa é que ainda está presente a idéia de que é necessário distanciar-se das pessoas que têm a doença pelo risco que estas oferecem.

\section{Prevenir-se contra as DSTs/AIDS - eu também?}

\section{Afirmação e negação do risco}

Os modos de prevenção da AIDS mencionados pelas adolescentes correspondem às vias de contaminação conhecidas. As adolescentes referem a necessidade de: conhecer a pessoa com quem se transa; de usar a camisinha; de evitar proximidade com portadores da doença; de evitar contato com secreções contaminadas; de realizar exames periódicos. Entre essas várias formas de prevenção a que destacam é o uso da camisinha, coerentemente com a associação mais direta que fazem entre AIDS e contato sexual.

Encontramos, em certos momentos, a percepção de que a AIDS é uma doença a que todos estão sujeitos, mas também a negação da possibilidade de ela fazer parte da própria vida. Uma das entrevistadas expressa uma certa contradição em relação a esse aspecto, como se pode observar no diálogo abaixo: a AIDS está perto ou longe de você?

\footnotetext{
"Não sei... Eu conheço os caras, acho que eles não tem essa doença. Depois camisinha é segura". (Obs: usa esporadicamente a carnisinha); Quem você acha que pode pegar AIDS? "Eu não sei. Tem hora que a pessoa tem o vírus e não aparece". Os namorados com os quais você transou podem ter o vírus? “Eu acho que não. Dá para ver quem está aidético” (Entrevista 8),
} 
Para algumas das adolescentes, a AIDS revela-se na aparência externa comprometida, especialmente no emagrecimento:

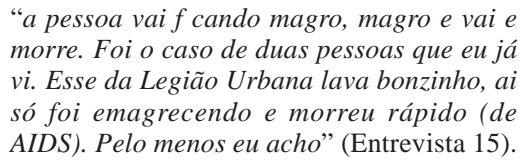

"a pessoa vai $f$ cando magro, magro e vai e morre. Foi o caso de duas pessoas que eu já vi. Esse da Legião Urbana lava bonzinho, ai só foi emagrecendo e morreu rápido (de AIDS). Pelo menos eu acho” (Entrevista 15).

Esses últimos dados sugerem a compreensão de que é possível o reconhecimento dos possíveis transmissores da doença e a seleção dos parceiros, leitura que certamente amplia a vulnerabilidade ${ }^{2}$ das adolescentes à doença.

Tal entendimento desconsidera o fato de a transmissão do vírus HIV ocorrer ainda que a doença não se desenvolva e se manifeste externamente.

Por um lado, identificamos entre o grupo um certo reconhecimento da doença e de sua gravidade, o que se pode considerar vantajoso, por outro, percebemos que o discurso acerca da AIDS é acompanhado de estereótipos e de uma certa negação, sobretudo da possibilidade de ela constituir-se em um risco próximo, que requer medidas de prevenção.

Isso é particularmente importante quando se coloca a questão do autocuidado preventivo. O não reconhecimento da AIDS como um problema a que todos estão sujeitos, de algum modo, freqüentemente resulta em práticas sexuais descuidadas, que expõe ao risco das DSTs/AIDS. Na medida em que se supõem distante tais problemas, não há razão para se prevenir contra eles.

A AIDS é, por vezes, expressa como uma doença próxima, possível de ser adquirida pelas depoentes, mas, igualmente, encontramos a compreensão de que só estariam sujeitas à doença se mantivessem relações sexuais com qualquer ou vários parceiros, numa possível traição do companheiro, ou se não fizessem uso da camisinha:

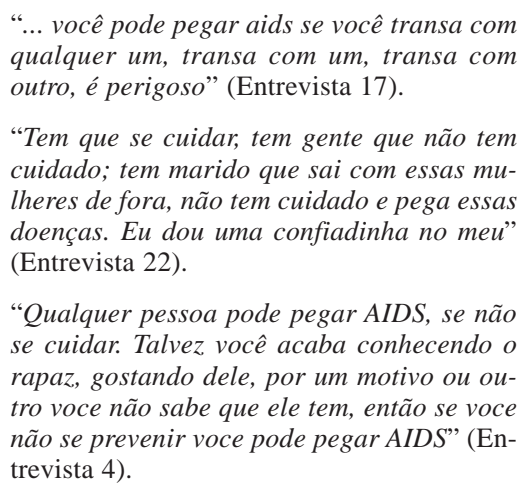

"Tem que se cuidar, tem gente que não tem cuidado; tem marido que sai com essas mulheres de fora, não tem cuidado e pega essas doenças. Eu dou uma confiadinha no meu" (Entrevista 22).

"Qualquer pessoa pode pegar AIDS, se não se cuidar. Talvez você acaba conhecendo o rapaz, gostando dele, por um motivo ou outro voce não sabe que ele tem, então se voce não se prevenir voce pode pegar AIDS" (Entrevista 4).

No discurso das adolescentes participantes deste estudo chama atenção o fato de, freqüentemente, não usarem o pronome na primeira pessoa. Não dizem se eu não usar a camisinha posso adquirir o vírus da AIDS; dizem: "se ela", "qualquer pessoa”, "se você", referindo-se sempre a um outro, o que reforça o entendimento de que a AIDS, enquanto uma possibilidade, vem acompanhada de medo e negação.

Frente a esses achados, uma questão que se coloca diz respeito ao que é, para essas adolescentes, o parceiro que oferece riscos, uma vez que estão presentes, claramente, as idéias de que aqueles que não têm manifestações externas da doença (AIDS) não são possíveis transmissores, de que o namorado ou o marido - aquele que se conhece (pela convivência), aquele de quem se gosta - não são possíveis agentes de contaminação (das DSTs/AIDS).

Parece que para essas adolescentes o fato de conhecerem o companheiro é suficiente para que se sintam protegidas. Também, vivenciando situações onde supostamente esteja presente a monogamia. O seu entendimento é o de que por serem casadas ou por não terem relações sexuais com qualquer um não estão sujeitas ao vírus da doença. Certamente, o conhecer a pessoa com quem se transa não é garantia contra a AIDS ou qualquer outra DST. Porém, para essas adolescentes, morar junto, ter contato há algum tempo, ter um parceiro único ou estar casada, de algum modo as protege do problema.

Identifica-se, então, que a atitude preventiva depende, pelo menos em parte, mais da identificação dos riscos a que estão sujeitas, do que propriamente das informações que tenham acumulado acerca do modo como as DSTs/ AIDS podem ser sexualmente transmitidas/prevenidas, o que nos leva a questionar as razões pelas quais tais adolescentes negam a possibilidade de alguém conhecido ser um possível transmissor.

Para o grupo estudado a idéia de risco mostra-se incompatível com o afeto, o que nos leva a considerar que, em nossa cultura, comumente, a sexualidade feminina é exercida atraves da permissão do amor e da negação de si (BARBOSA \& VlLLELA, 1996). Evitar situações de risco implicaria em uma atitude ativa da adolescente, de auto-valorização, de cuidado com a própria vida, e isto se contrapõe à visão predominante de amor que valoriza a negação de si em função do outro.

Os adolescentes, em nossa sociedade, estão também conquistando independência e apren-

2 O termo vulnerabilidade diz respeito ao controle sobre o risco de adquirir o HIV ou outra DST; refere-se a maior ou menor chance de se infectar ou de se proteger (PIMENTA, PASSARELLI, SANTOS \& NEGRÃO, 1998). 
dendo a lidar com ela, e certamente seus comportamentos manifestam-se repletos de contradições, entre o desejo/fantasia de serem protegidas (pelo outro) e o autocontrole/responsabilização pelos próprios aios (CAVALCANTI, 1988).

Isto é ainda mais complicado para adolescentes mulheres, pela educação que recebem, que as submetem, em alguma medida, aos valores masculinos e à negação de seus próprios desejos e necessidades. Adicotomia sexual homem/mulher, com desvalorização do feminino, concede ao homem a condução das relações afetivo-sexuais (GTFFEN \& LOWNDES, 1995). Assim, no campo das relações interpessoais, é geralmente o companheiro quem dita as regras para o relacionamento.

A problemática da prevenção das DSTs/ AIDS evidencia-se ainda mais quando olhamos para as experiências das adolescentes sujeitos deste estudo, especialmente das que já iniciaram a atividade sexual. No campo do vivido as contradições sobre a prevenção das DSTs/ AIDS, reveladas nos discursos, apresentam-se mais agudamente.

Por um lado, encontramos entre todas a referências camisinha como forma de prevenção de riscos e, entre algumas, a compreensão de que o sexo com muitos parceiros ou com alguém desconhecido é menos seguro, por outro, identificamos que a camisinha eventualmente fez ou faz parte das experiências do grupo que havia iniciado relações sexuais.

O que constatamos em nosso estudo é que adolescentes acumulam certas infommações sobre os meios de prevenção em relação à transmissão sexual das DSTs/AIDS. Referem afirmativamente a importância do uso da camisinha - sabem para quê e como se usa - mas não a utilizam continuamente como prática preventiva em suas relações sexusis. Contrariamente, acreditam que a necessidade existe para outros, nem sempre se vendo em situações de risco, tanto que entre as que iniciaram práticas sexuais, encontra-se a negação do uso de preservativo ou o uso esporádico.

O uso da camisinha é mencionado em situações em que não se conhecia o parceiro ou em função da preocupação com uma possível DST ou gravidez:

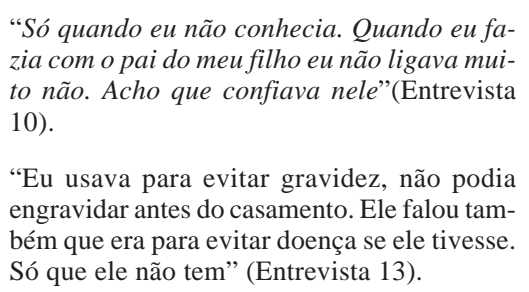

"Só quando eu não conhecia. Quando eu fazia com o pai do meu filho eu não ligava muito não. Acho que confiava nele”(Entrevista 10).

“Eu usava para evitar gravidez, não podia engravidar antes do casamento. Ele falou também que era para evitar doença se ele tivesse. Só que ele não tem” (Entrevista 13).

LOYOLA (1995) e GUIMARÃES (1994) também encontraram em seus estudos que o uso da camisinha nas relações sexuais ocorre sobretudo em função da preocupação com uma possivel gravidez e não para a prevenção das DSTs/AIDS, uma vez que aquela é vista como mais provável e porque tal preocupação é mais aceitável pelos companheiros.

Entre algumas das adolescentes que entrevistamos, contudo, nem mesmo a preocupação com uma possível gravidez as levou ao uso do condon (ou outro recurso); a condição do que fazer para evitá-la parece ter sido colocada nas mãos do companheiro, tanto que apresentaram como justificativa para o não uso do preservativo o incômodo referido pelo parceiro ou o fato de terem um par fixo e serem cobradas a confiar nele:

“.. ele não usa não. Ele fala que se fosse rapaz da rua, solteiro, que pegasse menina de boate, aisim era perigoso" (Entrevista 22).

Os dados encontrados revelam que entre as adolescentes que já tinham experiência sexual, a maioria a iniciou sem planejá-la; algumas clandestinamente. Várias não usaram preservativo na primeira relação. Para algumas, a preocupação maior girava em torno do que seria ou o que sentiriam no ato sexual.

A questão da prevenção parece-nos ainda mais problemática pelo fato de algumas adolescentes revelarem que se sentem inibidas para conversar com seus parceiros sobre sexo, sobre seus desejos, necessidades e sobre a prevenção das DSTs/ AIDS ou mesmo de uma gestação não desejada.

A ausência de diálogo acerca do exercício da sexualidade, presente na sociedade, associada aos preconceitos, estereótipos e moralismos em torno da questão (CONCEIÇÃO, 1988; RIECHELMANN, 1993), certamente demarcam tal dificuldade e interferem no modo como as adolescentes lidam com a troca em torno de sua sexualidade/sexo e a questão da prevenção das DSTs/AIDS.

Constatamos, entre as informantes que participaram do estudo, um certo desconhecimento especialmente sobre a AIDS e sua prevenção. Este é um problema não desejado por elas. Em alguma medida, vêem-se em possíveis situações de risco. Entretanto, a prevenção através do uso da camisrnha, na maioria das vezes, não fez ou não faz parte das suas experiências. O fato de as adolescentes entrevistadas possuírem um mínimo de informações não as leva a atitudes coerentes.

Esta é uma constatação fundamental quando se pensa a questão da prevenção das DSTs/ AIDS e a explicação para a dissociação entre ter a informação e a prática da prevenção, ainda que complexa, precisa ser buscada. 
A adolescência, em nossa sociedade, é fase em que ocorrem profundas e rápidas transformações - fisicas, emocionais, relacionais, de identidade e expressão da sexualidade. É uma época rica em manifestações emocionais, caracterizada pela ambigüidade de papéis (mfanfil/adulto), pela mudança de valores e por dificuldades frente à busca de independência. (CAVALCANTI, 1988). A adolescência é vivida com inúmeras incertezas, com independência-dependência, com medos, enfrentamentos e recuos, coerências e incoerências. Quase tudo é novo para os adolescentes e isto dificulta o lidar com a própria vida e a de outros. Contrariamente, identificar situações de risco e adotar medidas preventivas coerentes exigem uma postura ativa, certa maturidade emocional, que, em nossa cultura, encontra-se em construção nessa fase da vida.

No campo da sexualidade, as relações afetivas na adolescência ganham novas características; a curiosidade e o impulso para o sexo aumentam; os adolescentes lidam com novas cobranças internas e externas - de desempenho de papéis sociais (femininos/masculinos). No geral, agem impulsionados por seus desejos; submetem-se às cobranças de seu grupo social, nem sempre dimensionando implicações ligadas ao seu comportamento. O medo que sentem é muitas vezes gerador de uma certa onipotência, de modo que negam problemas, agem de forma imediatista e crêem firmemente que se isentarão de determinadas complicações (CAVALCANTI, 1988; TOLOSA, 1988).

Assim, as atividades sexuais na adolescência sào quase sempre não planejadas, o que acaba sendo incrementado pelo fato de serem clandestinas (como encontramos neste estudo). A instabilidade emocional presente nesta fase da vida, a dificuldade de decidir a respeito do que se quer, a dificuldade de lidar com o próprio corpo e o do outro, o pensamento idealizador de soluções e negador de possibilidades reais, entre outros aspectos, possivelmente são fatores que, em alguma medida, acabam por delimitar o modo como o grupo em questão comporta-se frente às DSTs/AIDS.

Além disso, é preciso considerar que as mulheres são educadas para a passividade, para acatar as decisões masculinas. Assim, projetam o cuidado de si no companheiro; tem dificuldades para dizer não, para colocar os seus limites. Como vivemos em uma sociedade culturalmente machista, na qual desde cedo a mulher é educada para viver segundo valores masculinos, muitas vezes ela é subjugada pelo companheiro, vendose forçada a acatar suas ideias e praticar o sexo conforme sua decisão (GIFFEN \& L011VNDES,
1995). Sabemos que tal situação já foi mais marcante no passado e que, hoje, em alguma medida, a mulher vem conquistando espaço para se colocar e a suas idéias e vontades. Porém, nesse sentido, ainda há muito a transformar. No campo da sexualidade, como constatamos através do discurso das adolescentes que entrevistamos, o homem ainda se sente no direito de negar o uso do preservativo e a adolescente na obrigação de não exigi-lo. A dificuldade em dialogar sobre sexo, afetos, desejos, cuidados com a própria saúde ainda parece ser muito presente. Certamente essas são razões que explicam, em parte, o acometimento das DSTs/AIDS entre mulheres adolescentes o que reforça a necessidade de se abrirem espaços para a reeducação sexual, nos quais a adolescente mulher resgate/conquiste autocontrole da própria vida e corpo, adquirindo condições para dialogar com seus companheiros, colocando-lhes limites e a si mesmas, protegendo a própria vida e saúde e a de outros.

\section{PREVENÇÃO DAS DSTS/AIDS: QUESTÃO DE INFORMAÇÃO OU EDUCAÇÃO?}

Vimos que o reconhecimento de problemas como as DSTs/AIDS, e sobre modos de prevenilas, entre as adolescentes entrevistadas, não resulta necessariamente em práticas preventivas, uma vez que encontramos tanto a ausência quanto a presença de infommação combinando-se com práticas sexuais descuidadas.

Obviamente tal achado não fala contra o acesso à mfommação, pois este é essencial quando se coloca em questão a prevenção dos problemas em foco. Porém, informação não é tudo. Se levarmos em consideração os dados apresentados nesta pesquisa, mais do que acesso à infommação revela-se essencial o acesso à educação ou reeducação sexual, baseada na interação entre conhecimentos, valores e ações. Devemos, então, questionar que educação favoreceria tal inter-relação.

Nesse sentido, é preciso considerar que há um tipo de educação, instalada em nossa sociedade, que se volta para a inserção harmoniosa dos sujeitos em sua estrutura. Trata-se de uma educação que se volta à reprodução do sistema social dominante. Segundo FREIRE (1987), esta é uma educação que gera alienação, a ausência de questionamentos dos diferentes interesses, das divisões, hierarquias e desigualdades sociais.

Mas, numa outra direção, encontramos também uma educação (não predominante) voltada à formação de homens conscientes, ativos, situados em relação às contradições existentes e engajados na luta e resistência à dominação e dis- 
criminações de qualquer ordem (de classes gênero, etnias, e outras). Trata-se de uma educação voltada para a cidadania e construção de uma sociedade mais democrática. Esta educação, apontada por FREIRE (1987), preocupa-se com a ação crítica do homem sobre a realidade, pois crê que este é sujeito que constrói e reconstrói a vida. Seu instrumento central é a conscientização, que propicia condições para mudar o estabelecido, na direção da libertação dos homens da rede social de opressão-repressão. Nela, os seres humanos são vistos como inseridos em contextos socioculturais específicos, como seres da praxis, que ao agirem/ refletirem tornarem-se mais conscientes e comprometidos com a transformação. Os sujeitos não são meros armazenadores de informações, mas construtores da cultura, pela atividade crítica e criadora, produzida com a reflexão e conscientização sobre a realidade vivida.

No que se refere à sexualidade, a educação, da primeira perspectiva, é a que se volta para o controle e repressão de seu exercício, com a finalidade de manter harmonia com as regras estabelecidas (CONCEIÇÃO, 1988). Trata-se de uma educação que anula o questionamento, as diferenças, e modela o uso do corpo, a manifestação dos afetos, dos desejos e as inter-relações entre pessoas e grupos. Nela, a sexualidade livre de repressão é vista como ameaça à ordem social estabelecida. Sexualidade responsável é sinônimo de resposta a padrões sociais estabelecidos para o sexo, corpo, relações afetivas, entre outros processos. As diferentes instituições sociais têm tido um papel importante nesse tipo de educação - através do reforço aos estereótipos que confrontam e hierarquizam o masculino e feminino, através da negação do corpo sexualizado, do reforço à relação sexo-família-reprodução e do olhar biologizante sobre a sexualidade.

Da segunda perspectiva, a educação para o exercício da sexualidade é baseada na valorização do ser humano, no questionamento e libertação dos padrões sociais de dominação e opressão sobre os sujeitos (CONCEIÇÃO, 1988). Diz respeito a uma educação voltada para a conquista do direito ao prazer, para a prática sexual segura, sem preconceitos - contra a lirnitação do sexo à reprodução, contra a hierarquização sexual e discriminação das diferenças. É uma educação que busca a conscientização pelo questionamento, pela participação, pelo posicionamento critico e responsável.

O enfrentamento de problemas como as DSTs/AIDS, considerada a sua relação com a sexualidade e a educação formal, requer a formação de indivíduos capazes de conviver de modo crítico e responsável com a própria sexualidade e a de outros. Identificamos nesta pesquisa que a percepção e a prevenção de riscos para os problemas em questão têm suporte em uma subjetividade que integra conhecimentos, afetividade e aspectos socioculturais. Assim, quando se pensa a educação sexual sistemática, dirigida a adolescentes, essa subjetividade precisa ser considerada. Quando se intenciona a prevenção de situações de risco, o trabalho educativo deve articular informação, crítica aos padrões culturais e consideração à afetividade presente no campo da sexualidade, de modo a desenvolver o respeito a si e a necessidades de outros, uma relação natural com o corpo, com o prazer, com o sexo, e o questionamento dos estereótipos e preconceitos. SCHALL \& STRUCHINER (1995) chamam atenção para o fato de que a educação para a mudança, no campo da sexualidade, requer consideração ao universo dos valores, experiências e afetos em suas articulações com aspectos socioculturais que os organizam.

No encaminhamento dessa prática educativa a abordagem e o modo de conduzi-la são fundamentais e um aspecto a ser considerado é o da distância entre o saber cognitivo e o fazer, como nos alerta o discurso anteriormente analisado. $\mathrm{O}$ primeiro nível de conhecimento certamente é importante, mas, no geral, insuficiente para provocar novos padrões de ação. A consideração aos aspectos afetivos/interativos, ligados ao comportamento humano/adolescente, é essencial para engendrar novas atitudes e ações.

O desenvolvimento da auto-estima e da responsabilidade social, que significa fortalecer a base emocional da consciência, é fundamental para a mudança de valores e comportamentos (SCHALL \& STRUCHINER, 1995). Nesse sentido, a construção de novos conceitos deve se dar a partir de situações de autovalorização e de inserção dos sujeitos em situações semelhantes às vividas, através do compartilhamento e busca de soluções conjuntas frente a situações em que se avaliem os códigos sociais a que se está submetido. No que se refere aos adolescentes, é preciso lembrar que estes estão fortemente pressionados pelo grupo, buscando auto-afirmação, daí ser importante a valorização de situações que trabalhem o universo das comoções e a avaliação dos padrões sociais e grupais vividos.

No que se refere à sexualidade, a educação, da pnmeira perspectiva, é a que se volta para o controle e repressão de seu exercício, com a finalidade de manter harmonia com as regras estabelecidas (CONCEIÇÃO, 1988). Trata-se de uma educação que anula o questionamento, as diferenças, e modela o uso do corpo, a manifestação dos afetos, dos desejos e as inter-relações en- 
tre pessoas e grupos. Nela, a sexualidade livre de repressão é vista como ameaça à ordem social estabelecida. Sexualidade responsável é sinônimo de resposta a padrões sociais estabelecidos para o sexo, corpo, relações afetivas, entre outros processos. As diferentes instituições sociais têm tido um papel importante nesse tipo de educação - através do reforço aos estereótipos que confrontam e hierarquizam o masculino e feminino, através da negação do corpo sexualizado, do reforço à relação sexo-familia-reprodução e do olhar biologizante sobre a sexualidade.

Da segunda perspectiva, a educação para o exercício da sexualidade é baseada na valorização do ser humano, no questionamento e libertação dos padrões sociais de dominação e opressão sobre os sujeitos (CONCEIÇÃO, 1988). Diz respeito a uma educação voltada para a conquista do direito ao prazer, para a prática sexual segura, sem preconceitos - contra a limitação do sexo à reprodução, contra a hierarquização sexual e discriminação das diferenças. É uma educação que busca a conscientização pelo questionamento, pela participação, pelo posicionamento critico e responsável.

O enfrentamento de problemas como as DSTs/AIDS, considerada a sua relação com a sexualidade e a educação formal, requer a formação de indivíduos capazes de conviver de modo crítico e responsável com a própria sexualidade e a de outros. Identificamos nesta pesquisa que a percepção e a prevenção de riscos para os problemas em questão têm suporte em uma subjetividade que integra conhecimentos, afetividade e aspectos socioculturais. Assim quando se pensa a educação sexual sistemática, dirigida a adolescentes, essa subjehvidade precisa ser considerada. Quando se intenciona a prevenção de situações de risco, o trabalho educativo deve articular informação, crítica aos padrões culturais e consideração à afetividade presente no campo da sexualidade, de modo a desenvolver o respeito a si e a necessidades de outros, uma relação natural com o corpo, com o prazer, com o sexo, e o questionamento dos estereótipos e preconceitos. SCHALL \& STRUCHINER (1995) chamam atenção para o fato de que a educação para a mudança, no campo da sexualidade, requer consideração ao universo dos valores, experiências e afetos em suas articulações com aspectos socioculturais que os organizam.

No encaminhamento dessa prática educativa a abordagem e o modo de conduzi-la são fundamentais e um aspecto a ser considerado é o da distância entre o saber cogiutivo e o fazer, como nos alerta o discurso anteriormente analisado. $\mathrm{O}$ primeiro nível de conhecimento certamente é im- portante, mas, no geral, insuficiente para provocar novos padrões de ação. A consideração aos aspectos afetivos/mterativos, ligados ao comportamento humano/adolescente, é essencial para engendrar novas atitudes e ações.

O desenvolvimento da auto-estima e da responsabilidade social, que significa fortalecer a base emocional da consciência é fundamental para a mudança de valores e comportamentos (SCHALL \& STRUCHINER, 1995). Nesse sentido, a construção de novos conceitos deve se dar a partir de situações de autovalorização e de inserção dos sujeitos em situações semelhantes às vividas, através do compartilhamento ebus ca de soluções conjuntas frente a situações em que se avaliem os códigos sociais a que se está submetido. No que se refere aos adolescentes, é preciso lembrar que estes estão fortemente pressionados pelo grupo, buscando auto-afirmação, daí ser importante a valorização de situações que trabalhem o universo das emoções e a avaliação dos padrões sociais e grupais vividos.

Não que seja possível estabelecer uma correlação direta entre educação e mudança de comportamentos. Segundo BINSWANGER (apud BRASIL, 1994), os comportamentos possuem: uma dimensão íntima - relacionada à sua predisposição/motivação para o fazer; uma dimensão interativa - fruto do feedback do(s) grupo(s) de contato; uma dimensão social - advinda de normatizações, controle social, de novos valores e suporte social para o agir, e uma dimensão física - derivada das influências do habitat. Contudo, entendemos que a educação (ou reeducação) sexual que favorece mudanças comportarnentais é aquela que valoriza a dimensão interpessoal, pautada no respeito, na liberdade própria e do outro de estabelecer seus próprios parâmetros e comportamentos.

Nesse sentido, cabe ao educador valorizar os adolescentes como sujeitos com potencialidades, respeitando os seus conhecimentos, valores e comportamentos. O estabelecimento de um vínculo afetivo e relacionamento de confiança é fundamental, a partir da consideração às condições de vida e subjetividades do grupo (SAYÃO, 1997).

A comunicação dialógica, a partir das percepções, vivências e interesses do grupo é a mais adequada a esta forma de relação (MILET \& MARCONI, 1993; SCHALL \& STRUCHINER, 1995). El a inclui a participação dos adolescentes na definição dos conhecimentos a serem construídos e reconstruídos. Abrange, tambem, uma comunicação horizontal, baseada no respeito ao saber, interesses e potencialidades dos adolescentes, no estímulo contínuo, respaldado em 
infommações necessárias à compreensão/exame dos temas postos em discussão em suas várias interpretações. Trata-se de uma comunicação que aceita a fomma como os adolescentes freqüentemente reagem ao tema, com uma linguagem própria permeada pela malícia, brincadeiras e gozações (SAYÃO, 1997).

O trabalho educativo deve caractenzar-se como participativo. O processo todo deve dar-se com base no compartilhamento de idéias, trocas, questionamentos, expressão de experiências e valores dos adolescentes. Isto, particularmente, através da reflexão sobre situações reais, para novos entendimentos e identificação de alternativas frente aos problemas, necessidades e processos vividos no campo da sexualidade.

A escuta é muito importante, o perceber nas enbrelinhas, para possibilitar uma fala que favoreça ao adolescente encontrar-se e se compreender; o espaço do anonimato também, para permitir que a dúvida seja esclarecida, quando se quer privacidade, quando se quer evitar gozações e comentários sobre a própria intimidade (SAYÃO, 1997).

Além do pensar, refletir, discutir, as experiências que envolvem o sentir, o bnncar, o se emocionar, o tocar, o se solidarizar também são fundamentais para a formação de uma visão e pratica mais integrada no campo da sexualidade (MILET \& MARCONI, 1993).

Abrir espaço para a exposição de medos, convicções, curiosidades e valores de relevante importância pois a informação nova só será significativa se responder ao universo das vivências e motivações dos adolescentes (SAYÃO, 1997).

Para que o processo seja educativo é preciso considerar que os adolescentes com os quais se trabalha vivem uma determinada história, desejam, pensam, sentem - substratos a partir dos quais o diálogo deve ser encaminhado. Para isto, a educação precisa estruturar-se a partir das características gerais e específicas do grupo e de seus interesses e necessidades, a serem levantados inicialmente e ao longo do processo (SAYÃO, 1997). Respostas a questões, como: em que condições econômicas, culturais, familiares vivem os adolescentes que participarão de um programa educativo, qual a faixa etária desses adolescentes, quais os padrões de identidade fèminina masculina a que estão sujeitos, que informações eles dispõem, quais são seus interesses, quais seus conhecimentos e valores, entre outras, são básicas ao encaminhamento de uma prática educativa sistemática.

Os educadores não podem colocar-se como modelo, como os que sabem, como os únicos que tem o que ensinar. Os homens educam-se entre si
(FREIRE, 1987). Assim, os profissionais devem abrir-se para aprender com os adolescentes, com suas ousadias e criatividade. Através da relação dialógica educador e educando devem colocar-se como sujeitos de um mesmo processo - o de crescimento.

Tudo deve ser considerado educativo: os conhecimentos, as relações estabelecidas, as posturas, os processos de ensinar-aprender (SAYÃO, 1997). Nesse sentido, os educadores precisam desenvolver a coerência para oferecer uma educação libertadora, valorizando a abertura, a troca, a criticidade, a criatiividade, a solidariedade elementos educativos em si mesmos.

\section{CONSIDERAÇÕES FINAIS}

O contato com as idéias, valores e práticas relacionados às DSTs/AIDS e sua prevenção, a partir do discurso de adolescentes mulheres, permite reafirmar a compreensão de que o trabalho educativo no campo da sexuaíidade, como uma alternativa ao enfrentamento daqueles problemas, deve ser contínuo e o mais amplo possível, abrangendo atividades integradas entre os diferentes setores sociais - serviços de saúde, escolas, meios de comunicação e famílias.

Educar em sexualidade é processo que exige o estabelecimento de parcerias e trabalho interdisciplinar. A articulação dos vários campos de saber e práticas e entre os profissionais da saúde e de outras áreas sociais, poderá permitir uma visão e abordagem mais ampla em torno da questão. Essa inter-relação é necessária ao enriquecimento das visões e práticas a serem encaminhadas.

Somente através de um exercício saudável da sexualidade é possível pensar a prevenção de problemas como as DSTs/AIDS. É, portanto, necessário que se estabeleça um amplo processo educativo, voltado às diferentes fases do desenvolvimento e aos diferentes segmentos sociais, visando a formação de indivíduos responsáveis frente ao exercício da sexualidade.

Voltado para os adolescentes, o trabalho educativo em sexualidade não deve se constituir em transmissão de crenças, valores e preconceitos sexuais ou em imposição de "verdades". Ao contrário, deve favorecer trocas sem dogmatismo, de forma que os sujeitos adolescentes possam expressar, refletir, discutir, questionar e optar livre e responsavelmente acerca de suas condutas no campo da afetividade e, especificamente, de sua vida sexual.

Amplamente, é preciso considerar que o enfrentamento dos problemas e necessidades de- 
batidos neste artigo não podem se dar fora do contexto das formulações políticas voltadas à saúde do adolescente, em função do alargamento das situações de risco a que está sujeito este segmento da população.

As mudanças econômicas e sociais das últimas décadas (industrialização, urbanização, avanço da ciência, tecnologização, revolução nos costumes e valores) têm, de algum modo, comprometido a saúde dos diferentes grupos sociais e, em particular, dos adolescentes, exigindo medidas amplas para a sua superacão.
É necessário que o grupo em questão seja alvo de ações integradas, desenvolvidas tanto por instituições governamentais, envolvendo os níveis federal, estadual e municipal, como por instituições não governamentais. Projetos devem ser encaminhadas - focalizando suas condições de vida e necessidades que dela derivam, considerando o acesso diferenciado a bens e recursos sociais. Saúde, sexualidade e prevenção das DSTs/AIDS questões importantes da adolescência - estão intimamente relacionadas e exigem um enfrentamento conjunto e extensivo às diferentes etapas da vida.

\begin{abstract}
In this paper, we discuss lhe knowledge adolescente have, their values and practices regarding STD/AIDS and theirprevention. Based on lhe research data, we emphasize lhe dissociation between having access to information and lhe adoption of prevention behaviors. In addition, we present some fundamental clemente to lhe design of educacional practices directed lo adolescente, taking into account lhe need for integration between knowledge, affectivity and social-cultural aspects.
\end{abstract}

Key-words: STD/AIDS; sexual education; sexuality; adolescence.

\section{REFERÊNCIAS BIBLIOGRÁFICAS}

ARRILHA, M.; CALAZANS, G. Sexualidade na adolescência: o que há de novo? In: COMISSÃO NACIONAL DE POPULAÇÃ̃ E DESENVOLVIMENTO. Jovens acontecendo na trilha das políticas públicas. Brasília, 1998. 2v. p.687-705.

BARBOSA, R.M.; VILLELA, W.V. A trajetória feminina da AIDS. In: PARKER, R.; GALVÃO, J. (Orgs.). Quebrando o silêncio: mulheres e AIDS no Brasil. Rio de Janeiro, Relume-Dumará: ABIA:IMS/ UFRJ, 1996. p.17-32.

BRASIL, Ministério da Educação e do Desporto. Secretaria de Projetos Educacionais Especiais. Diretrizes para uma politica educacional em sexualidade. Brasília, MEC/ SEPESPE, 1994.

BRASIL, Ministério da Saúde. Coordenação Nacional de Doenças Sexualmente Transmissíveis e AIDS. AIDS: boletim epidemiológico. Ano X., Número 3, junhÔagosto de 1997a.

BRASIL, Ministério da Saúde. Secretaria de Políticas de Saúde. Coordenação Nacional de DST e AIDS. AIDS no Brasil: um esforço conjunto governosociedade. Brasília, 1998.

BRASIL, Ministério da Saúde. Secretaria de Projetos Especiais de Saúde. Coordenação Nacional das DSTs/AIDS. Dados epidemiológicos. Brasília, 1997b. (Endeieço eletrônico: ht p// www.aids.gov.br).
CAN ELLA, P.R.B. Adolescência e doenças sexualmente transmissíveis. In: COMISSÃO NACIONAL DE ESTUDOS SOBRE AADOLESCÊNCIA. Adolescência hoje. São Paulo, Roca, 1988. p.l23-134.

CASTRO, A. Televisão e AIDS: questões para o planejamento. In: PITTA, A.M. da R (Org.). Saúde e comunicação: visibilidades e silêncios. São Paulo, Hucitec, Rio de Janeiro, Abrasco, 1995. p.166171.

CAVALCANTI, Rd.C. Adolescência. In: COMISSÃO NACIONAL DE ESTUDOS SOBRE A ADOLESCÊNCIA. Adolescência hoje. São Paulo, Roca, 1988. p.5-27.

CONCEIÇÃO, I.S.C. Educação sexual. In: COMISSÃ̃O NACIONAL DE ESTUDOS SOBRE AADOLESCÊNCIA. Adolescência oje. São Paulo, Roca, 1988. p.71-76.

CORRÊA da COSTA, A.A. Doenças sexualmente transmissiveis em meninos e meninas de rua freqüentadores da casa do Porto. Cuiabá, 1996. Monografia apresentada à Faculdade de Enfermagem e Nutrição da UFMT.

CUIABÁ, Fundação de Saúde. Dados populacionais do Distrito Sanitário Sul. Cuiabá, 1998.

FREIRE, R Pedagogia do oprimido. 17.ed. Rio de Janeiro, Paz e Terra, 1987.

GIFF N, K.; LOWNDES, C.M. Gêneros, sexualidades e doenças sexualmente transmissiveis. Trabalho Apresentado no I Congresso Brasileiro de Ciências Sociais em Saúde, Curitiba, 1995.

GOMES, R. Análise de dados em pesquisa qualitativa. In: MINAYO, M.C.d.S. (Org.). Pesqui- 
sa social: teoria, método e criatividade. Petrópolis, Vozes, 1994. Cap.4: p.67-80.

GUIMARÃES, C. D. Mulheres, sexualidade e AIDS : um projeto de prevenção. In: COSTA, A.d.O.; AMADO, T. (Orgs.). Alternativas escassas: saúde, sexualidade e reprodução na América Latina. São Paulo, Prodir/FCC - Rio de Janeiro,1994. Ed.34. p.249-281.e

LOYOLA, A. Percepção e prevenção da AIDS no Rio de Janeiro. In: AIDS e sexualidade: o ponto de vista das ciências humanas. Rio de Janeiro, Relume-Dumará, 1995. p.19-72.

MATO GROSSO, Secretaria de Saúde. Sistema de Informações de agravos de notif cação SUSDST/ AIDS. Mato Grosso, dezembro de 1997.

MATO GROSSO, Secretaria de Saúde. Sistema de Informações de agravos de notif cação SUSDST/ AIDS. Mato Grosso, janeiro de 1999.

MILET, M.E.; MARCONI, R Metodologia participativa na criação de material educativo com adolescentes. In: RIBEIRO, M. (Org.). Educação sexual: novas idéias, novas conquistas. Rio de Janeiro, Rosa dos Tempos, 1993. p.205229.

MONTEIRO, S. Projeto viva a vida: prevenindo a AIDS na escola. In: CZERESNIA, D.; SANTOS, E.M.; BARBOSA, R.H.S.; MONTEIRO, S. AIDS: pesquisa social e educação. São Paulo/Rio de Janeiro, Hucitec,1995.p.122-136.

OLIV EI RA, M.H.P. et. al. O conhecimento sobre a AIDS entre trabalhadores rurais. Revista Paulista de Enfermagem, 11(2): 77-80,1992.

PARKER, R. Introdução. In: PARKER, R. (Org.). Políticas, instituições e AIDS: enfrentando a epidemia no Brasil. Rio de Janeiro, Zahar Editor/ ABIA, 1997. p.7-1 5.

PARKER, R.; GALVÃO, J. introdução. In: PARKER, R.; GALVÃO, J. (Orgs.). Quehrando o silêncio: mulheres e AIDS no Brasil. Rio de Janeiro, RelumeDumará/ ABIA/ IMS/ UFRJ, 1996. p.7- 15.
PARKER, RG.; HERDT, G.; CARBALLO, M. Cultura sexual, transmissão do HIV e pesquisas sobre a AIDS. In: CZERESNIA, D.; MOREIRA DOS SANTOS, E.; BARBOSA, R.H.S.; MONTEIRO, S. AIDS: pesquisa social e educação. São Paulo, Hucitec, 1995. p. 17-45.

PIMENTA, C.; PASSARWELLI, C.; SANTOS, C.E.d.; NEGRÃO, I.R Nossa vida, nosso tempo. Coordenação Nacional DST/AIDS. Brasília, Boletim n.9, 1998.

RI ECHELMANN, J. C. A educação sexual no sistema de saúde. In: RIBEIRO, M. (Org.). Educação sexual: novas ideias, novas conquistas. Rio de Janeiro, Rosa dos Tempos, 1993. p.279304.

SAYÃO, R. Saber o sexo? Os problemas da informação sexual e o papel da escola. In: AQUINO, J.G. (Org.). Sexualidade na escola: alternativas teóricas e práticas. São Paulo, Summus, 1997. p.97105.

SHALL, V.T.; STRUCHINER, M. Educação no contexto da epidemia de HIV/AIDS: teorias e tendências pedagógicas. In: CZERESNIA, D.; MOREIRA DOS SANTOS, E.; BARBOSA, R.H.S.; MONTEIRO, S. AIDS: pesquisa social e educação. São Paulo, Hucitec,1995, p. 84-105.

SILVA, G.A. Desenvolvimento infantil e a sexualidade. In: SILVA, G.A.; MARTINS, M.C.T. Sexualidade na contramao: roteiro de orientação temática para pais, educadores e lideranças comunitárias. São Paulo,Paulus, 1995.p. 51-69.

TOLOSA, M. Adolescência e ideologia. In: COMISSÃO NACIONAL DE ESTUDOS SOBREAADOLESCENCIA. Adolescencia hoje. São Paulo, Roca, 1988. p. 35-37.

Recebido em 13/03/2000 Aprovado em 16/04/2000 